\title{
Evaluation of visible fluorescent elastomer tags implanted in marine medaka, Oryzias dancena
}

\author{
Jae Hyun Im ${ }^{1}$, Hyun Woo Gil², In-Seok Park ${ }^{2^{*}}$ (D) Cheol Young Choi ${ }^{2}$, Tae Ho Lee ${ }^{2}$, Kwang Yeol Yoo ${ }^{3}$, \\ Chi Hong Kim ${ }^{4}$ and Bong Seok Kim ${ }^{4}$
}

\begin{abstract}
The aim of this study was to assess visible implant fluorescent elastomer (VIE) tagging and stress response in marine medaka, Oryzias dancena. The experimental fish were anesthetized individually and marked with red, yellow, or green elastomer at each of the following three body locations: (1) the abdomen, (2) the back, and (3) the caudal vasculature. During 12 months, the accumulated survival rates of fish in the experimental treatments were not different among red, yellow, and green elastomers. The experimental fish retained $>85 \%$ of the tags injected in the back, $>70 \%$ of the tags injected in the caudal vasculature, and $>60 \%$ of the tags injected in the abdomen $(P<0.05)$. An important observation was that the abdomen site was associated with poor tag retention. For all injected sites, the red and green tags were able to be detected more easily than the yellow tags when observed under both visible and UV lights. Tag readability was lower for the abdomen site than for the other sites (back and caudal vasculature). Thus, VIE tags were easy to apply to marine medaka ( $<1 \mathrm{~min}$ per fish) and were readily visible when viewed under UV light.
\end{abstract}

Keywords: Marine medaka, Oryzias dancena, Readability, Visible fluorescent elastomer tag

\section{Background}

The marine medaka, Oryzias dancena, is nonindigenous to South Korea and is a bony fish with high tolerance to salinity because of its salinity adaptation mechanisms (Inoue and Takei, 2003). In addition to the studies of this euryhaline species, under various salinity conditions, it has been the subject of extensive ecotoxicogenomic research; this should extend the use of the marine medaka as a laboratory model for assessing its responses to salinity changes. Its viability under conditions of maximum tolerable salinity has been measured, and incubation time of fry was assessed by its ability to adapt to various salinity (Cho et al., 2010). This species was recently selected by $i$ MLMO (Institute of Marine Living Modified Organisms, Pukyong National University, Busan 608737 , Korea) for use in a project to evaluate living modified organisms. Consistent with this purpose, detailed information on its biology is being collected (Song et al., 2009; Nam et al., 2010), particularly related to its early

\footnotetext{
* Correspondence: ispark@kmou.ac.kr

2Division of Marine Bioscience, College of Ocean Science and Technology, Korea Maritime and Ocean University, 727 Taejong-ro, Yeong do-gu, Busan 49112, South Korea

Full list of author information is available at the end of the article
}

gonadogenesis, sexual differentiation, early ontogenesis, embryogenesis, and exceptional capacity for hyperosmoregulation and hypoosmoregulation. In addition, Kim et al. (Song et al., 2009) suggested that this species has a short interval between generations with spawning possible only for 60 days after hatching. A study of the effects of clove oil and lidocaine $\mathrm{HCl}$ on the species by Park et al. (2011) has contributed to the safe laboratory handling of this fish, which is required in many studies. The research discussed above has demonstrated that the marine medaka has the ideal characteristics for an experimental animal (Song et al., 2009; Nam et al., 2010; Park et al., 2011).

Identification of individuals is essential in studies of fish growth, migration, and mortality and in stock identification and stock selectivity for tracing particular fish populations (Crossland, 1980). Although short-term tag retention may suffice for some experiments, the effect of a tag on fish survival, behavior, growth, and recognition and the costs of the tagging technique need to be considered. However, traditional external tags (such as spaghetti or dart tags) are commonly lost soon after deployment (Crossland, 1980; Bergman et al., 1992) and can affect growth or survival 
(Crossland, 1976; Tong, 1978; McFarlane and Beamish, 1990; Serafy et al., 1995). Furthermore, these types of tags can only be read by recapturing the fish.

Devices that are located internally but are readable externally, such as acoustic tags, are often limited by short battery life or retention (Ralston and Horn, 1986), and sample sizes are limited by the expense involved. Problems associated with biological compatibility, reliability of identification, fouling of the tag by algae (Jones, 1987; Barrett, 1995), tag retention (Crossland, 1976; Parker, 1990), and external visibility of such devices have reduced confidence in the interpretation of results of in situ studies of reef fish ecology. A less frequently used approach is intrinsic identification, whereby cohorts are identified by size (Jones, 1987; Forrester, 1990) and individuals are recognized by variation in natural markings (Thompson and Jones, 1980; Connell and Jones, 1991) or wound scarring.

The latter approach has cost advantages, so does not influence behavior, but is subject to potentially substantial levels of observer error. Furthermore, many fish species lack unique natural markings and cannot be recognized without an artificial means of verifying identity. Passive integrated tag (PIT) method is the most commonly used. However, the body size of marine medaka is similar to that of PIT chips, so marine medaka is unsuitable for tagging PIT chips. The visible implant fluorescent elastomer (VIE) tag was developed primarily for tagging large batches of small or juvenile fish. The VIE system comprises a viscous liquid elastomer that sets to a pliable solid over a period of hours following application. The elastomer can be injected into transparent or translucent tissues to form a permanent biocompatible mark. When exposed to UV light and viewed through an amber filter, the compound fluoresces brightly. The tag size can easily be varied according to the requirements of the researcher and the size of the fish to be tagged. Thus far, the system has been used for the identification of groups or cohorts of juvenile reef fish (Frederick, 1997) and salmonids, but is also proving potentially effective in controlled laboratory studies of adult blue gills (Dewey and Zigler, 1996). As an externally visible but sub-dermally situated marking system, VIE tags are potentially able to eliminate many of the problems associated with other methods.

Tagging, weighing, measuring standard length, preparing fish for live shipment and transport, injecting vaccines and antibiotics, and collecting blood are causes to increasing stress (Dewey and Zigler, 1996). Stress responses can include physiological changes such as oxygen uptake and transfer, metabolic and hematological changes, mobilization of energy substrates, reallocation of energy away from growth and reproduction, and suppressive effects on immune functions (Schreck et al.,
2001; Redding and Schreck, 1983). These changes can increase disease susceptibility leading to increased mortality and subsequent economic losses (Schreck et al., 2001; Redding and Schreck, 1983). So, analysis of stress response can roughly examine the cause of mortality by tagging. The steroid hormone cortisol is widely accepted as an indicator of stress in fish, generally increasing after exposure to physical stressors (Schreck et al., 2001). Circulating cortisol levels are typically measured to determine the stress status of an individual fish (Redding and Schreck, 1983). Alternatively, whole-body cortisol levels have been used to assess the stress responses of the developing salmonids and flatfish because their blood volumes are insufficient to allow for the measurements of circulating cortisol (Redding and Schreck, 1983). Similarly, whole-body corticosteroids have been measured in smaller adult fish, including the threespined stickleback, Gasterosteus aculeatus (Pottinger et al., 2002), and the zebrafish, Danio rerio (Pottinger and Calder, 1995). In this study, we compared various tag colors for readability under visible and UV lights and assessed the likelihood of tag- or handling-related mortality, the retention rates of VIE tags placed, and the stress response in various body sites of marine medaka. So, suitability of VIE tag method in marine medaka was investigated by analysis of readability, mortality, and stress response.

\section{Methods}

The fish used in this experiment were adult marine medaka, O. dancena (mean body length \pm SD $35.1 \pm 3.42 \mathrm{~mm}$; mean body weight \pm SD $54.4 \pm 1.83 \mathrm{mg}$; age 10 months after hatched). Injection of the VIE tags into the treatment fish, and handling of the control fish, occurred on 16 February 2012. Following to the method of Park et al. (2011), all fish were anesthetized in 800 ppm lidocaine hydrochloride $/ \mathrm{NaHCO}_{3}$ at a water temperature of $10{ }^{\circ} \mathrm{C}$. The fish were sedated until they were completely immobile and then individually removed from the anesthetic solution, rinsed in fresh water, and placed on a flat surface for tagging.

Per group of 50, the fish were individually tagged with yellow, red, or green elastomer (Northwest Marine Technology Inc., Shaw Island, Washington, USA) at three body locations (Figs. 1 and 2a): (1) the surface of the abdomen, (2) the inside surface of the back, and (3) the surface of the caudal vasculature, and all experimental groups were triplicated. Control fish (50) were anesthetized but not marked. We used the VIE hand injection Master Kit (Northwest Marine Technology Inc., Shaw Island, Washington, USA) for tagging the fish. Following the kit protocol, the elastomer and curing agent were mixed at a ratio of 10:1 and the prepared elastomer was injected as a liquid $(0.3 \mathrm{~mL}$ per site). The 


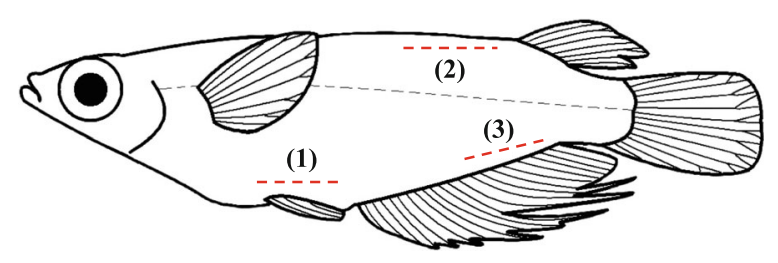

Fig. 1 Elastomer injection locations (red dotted lines) on marine medaka, Oryzias dancena: (1) the surface of the abdomen; (2) the inside surface of the back; and (3) the surface of the caudal vasculature

instruments used are shown in Fig. 2b. Tagged fish were divided into different tag colors and injection sites in tanks. The fish were held in 18 flow-through fiberreinforced plastic tanks $(50 \times 20 \times 20 \mathrm{~cm}$; water volume 2 L) supplied with filtered seawater. The bottom of each tank was fitted with a black sheet to facilitate for observation of the tag. The flow rate was $2 \mathrm{~L} / \mathrm{min} / \operatorname{tank}$, and the mean water temperature was $26 \pm 2.5^{\circ} \mathrm{C}$. A common day-night cycle was established, and all tanks were covered with netting to retain the fish in the tanks. Throughout the 12-month trial, the fish were fed daily to satiation using a dry commercial flounder feed (Agribrand Furina Korea Co., Korea) that was alternated with a formulated Artemia diet. The food was placed on the aquarium floor so that it could be eaten within $2 \mathrm{~h}$.

The survival rate, tag retention, and detection of tags (under visible and UV lights) were recorded at 2-month

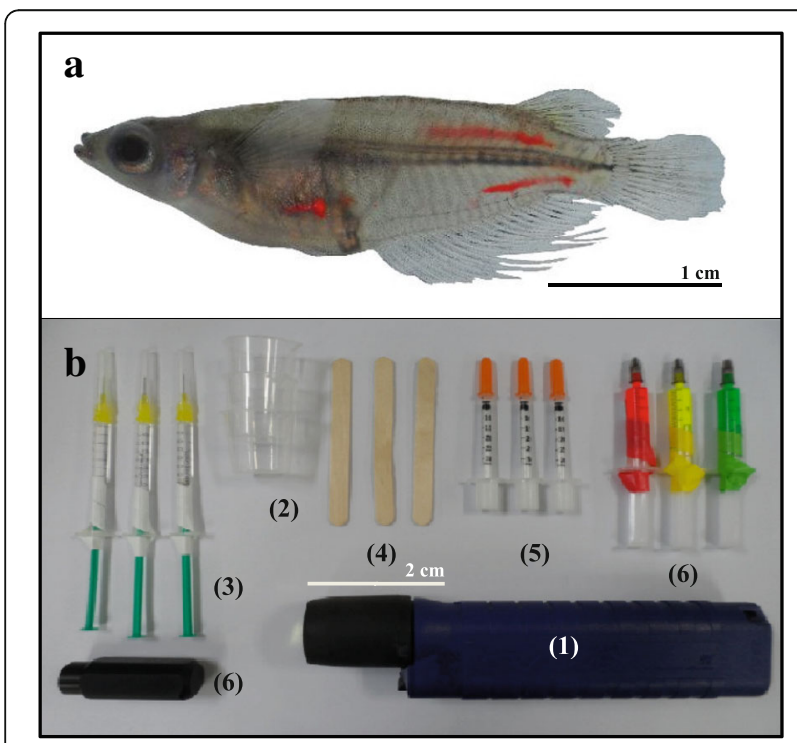

Fig. 2 External morphology of marine medaka, Oryzias dancena, tagged with visible implant fluorescent elastomer (VIE), showing the yellow tags at each tagging site under UV light (a) and (b) the VIE kit (Northwest Marine Technology, Shaw Island, Washington) including the UV lamp (1), mixing beaker (2), silicon (3), mixing stack (4), colored elastomer in a syringe (5), and the injection syringe (6) intervals. The tanks were checked daily for dead fish, which if present were removed and fixed in $10 \%$ neutral formalin solution. The marking with the various colors at the three sites was observed visually from a distance of $30 \mathrm{~cm}$ under ambient visible light and UV light and measured the differentiation rate of each group after 1 month. Tag retention data for the dead fish were used to calculate the percent tag retention up to the date that the fish died, but were not used in the subsequent calculations (Zerrenner et al., 1997).

To observe the effects of stress on the whole-body cortisol, glucose, and lactic acid levels of fish under VIE tag injection, we injected the VIE tag in the abdomen, the back, and the caudal vasculature, respectively, and 90 samples were used in each site. The stress responses of the experimental fish were measured at $0,1,6,12,24$, and $48 \mathrm{~h}$. Fifteen samples were used in each measured time. Control fish were not injected VIE tag, but their cortisol levels were measured. For these measurements, 150 fish were used in each experimental group, and no distinction was made between male and female fish. We measured the whole-body cortisol, glucose, and lactic acid levels of the control fish before the experiment. Individual fish were blotted onto paper towels to remove excess water, immediately frozen in liquid nitrogen for $10-30 \mathrm{~s}$, and placed in individual $5.0 \mathrm{~mL}$ plastic screw cap centrifuge tubes. The samples were stored at $-80{ }^{\circ} \mathrm{C}$ until we extracted the cortisol, glucose, and lactic acid. The term "whole-body cortisol" is used to describe the portion of corticosteroid extracted and measured with a cortisol-specific radioimmunoassay (Pottinger et al., 2002). Whole-body glucose concentration was analyzed according to the methodology of Raabo and Terkildsen (1960) (Kit 510, Sigma, St Louis, MO, USA), where the production of $\mathrm{H}_{2} \mathrm{O}_{2}$ by glucose oxidase in the presence of $o$-dianisidine was evaluated as an absorbance increase at $450 \mathrm{~nm}$. The lactic acid concentrations were analyzed using blood automatic analysis (Boehringer Mannheim Reflotron, Germany).

All measured data were induced by triplicate experiments from all experimental samples. Differences in survival rate between control and experimental groups were assessed using the $t$ test (Cody and Smith, 1991), and the tag retention rate (\%) among tagging sites was assessed using a one-way ANOVA and Duncan's multiple range test (Duncan, 1955). The differences were considered to be significant at a probability of 0.05 .

\section{Results}

Table 1 shows the retention rate of the VIE tags at each site for marine medaka, O. dancena. During the experiment, there was no difference in tag retention among the various tag colors for the abdomen site, but the tag retention rate for this site was different from that of the 
Table 1 Tagging rate using the naked eye and the UV lamp of visible implant fluorescent elastomer (VIE) tags in each site of marine medaka, Oryzias dancena, from 0 to 12 months after VIE tagging

\begin{tabular}{lllll}
\hline \multirow{2}{*}{ Month } & Color & \multicolumn{3}{l}{ Tagging rate (\%) } \\
\cline { 3 - 5 } & & Abdomen & Back & Caudal vasculature \\
\hline 1 & Red & $57.4 \pm 3.26^{\mathrm{a}}$ & $99.3 \pm 0.16^{\mathrm{b}}$ & $99.0 \pm 0.22^{\mathrm{b}}$ \\
& Green & $77.6 \pm 1.11^{\mathrm{a}}$ & $94.7 \pm 0.85^{\mathrm{b}}$ & $99.3 \pm 0.10^{\mathrm{c}}$ \\
& Yellow & $74.3 \pm 1.48^{\mathrm{a}}$ & $94.9 \pm 0.80^{\mathrm{b}}$ & $95.4 \pm 0.67^{\mathrm{b}}$ \\
& Red & $60.6 \pm 2.32^{\mathrm{a}}$ & $93.5 \pm 1.03^{\mathrm{b}}$ & $99.4 \pm 0.05^{\mathrm{c}}$ \\
& Green & $76.4 \pm 0.87^{\mathrm{a}}$ & $93.8 \pm 0.58^{\mathrm{b}}$ & $95.6 \pm 0.57^{\mathrm{c}}$ \\
& Yellow & $73.2 \pm 1.75^{\mathrm{a}}$ & $94.9 \pm 0.99^{\mathrm{b}}$ & $92.9 \pm 2.10^{\mathrm{b}}$ \\
& Red & $57.3 \pm 3.74^{\mathrm{a}}$ & $92.0 \pm 1.52^{\mathrm{b}}$ & $96.5 \pm 0.60^{\mathrm{c}}$ \\
& Green & $80.7 \pm 2.10^{\mathrm{a}}$ & $92.6 \pm 0.83^{\mathrm{b}}$ & $94.9 \pm 0.81^{\mathrm{b}}$ \\
& Yellow & $75.1 \pm 1.68^{\mathrm{a}}$ & $95.4 \pm 1.00^{\mathrm{b}}$ & $92.2 \pm 1.88^{\mathrm{b}}$ \\
& Red & $64.4 \pm 3.19^{\mathrm{a}}$ & $93.4 \pm 0.67^{\mathrm{b}}$ & $97.5 \pm 0.80^{\mathrm{c}}$ \\
& Green & $79.0 \pm 1.46^{\mathrm{a}}$ & $89.8 \pm 1.79^{\mathrm{b}}$ & $99.1 \pm 0.09^{\mathrm{c}}$ \\
& Yellow & $75.9 \pm 2.00^{\mathrm{a}}$ & $95.5 \pm 0.73^{\mathrm{b}}$ & $94.4 \pm 1.73^{\mathrm{b}}$ \\
& Red & $67.2 \pm 3.05^{\mathrm{a}}$ & $90.5 \pm 1.31^{\mathrm{b}}$ & $96.6 \pm 0.66^{\mathrm{c}}$ \\
& Green & $79.5 \pm 1.96^{\mathrm{a}}$ & $94.4 \pm 0.74^{\mathrm{b}}$ & $97.2 \pm 0.38^{\mathrm{c}}$ \\
& Yellow & $70.4 \pm 1.21^{\mathrm{a}}$ & $94.6 \pm 0.94^{\mathrm{b}}$ & $95.6 \pm 0.86^{\mathrm{b}}$ \\
\hline
\end{tabular}

Samples tagged with VIE were investigated. Values are mean \pm S.E. $(n=50)$. The experiment was performed in triplicate. The values in each column that do not share a common superscript are significantly different from one another $(P<0.05)$

back and caudal vasculature sites. For the abdomen site, the retention (\%) of the elastomer at 1 month were $57.4 \pm 3.26$ for red, $77.6 \pm 1.11$ for green, and $74.3 \pm 1.48$ for yellow but at 6 months were $57.3 \pm 3.74$ (red), $80.7 \pm 2.10$ (green), and $75.1 \pm 1.68$ (yellow). And in this term, the green and yellow values were significantly higher than the red value. However, the retention rate of the abdomen site was not affected by color. In summary, the retention rate for red was $67.2 \pm 3.05$, for green was $79.5 \pm 1.96$, and for yellow was $70.4 \pm 1.21$. For the back site at 1 month, the retention rate for red was $99.3 \pm 0.16$ and for green was $94.7 \pm 0.85$. The retention rate for yellow was $94.9 \pm 0.80$. After 9 months, the values had declined to $93.4 \pm 0.67,89.8 \pm 1.79$, and $95.5 \pm 0.73$ along red, green, and yellow, respectively. These values show that the VIE was removed from the tagged site by the time in each site. In conclusion, at 12 months, the tag retention rates for the back were $90.5 \pm 1.31,94.4 \pm 0.74$, and $94.6 \pm 0.94$ for the red, green, and yellow elastomers, respectively. For the caudal vasculature, there were no significant differences $(P<0.05)$ among the elastomer colors (red, $99.0 \pm 0.22$; green, $99.3 \pm 0.10$; yellow, $95.4 \pm 0.67$ ), but at the end of the experiment, the values were $96.6 \pm 0.66,97.2 \pm 0.38$, and $95.6 \pm 0.86$, respectively. Among the three colors, the tag retention rate for the back was the highest $(P<0.05)$, followed by that of the caudal vasculature
Table 2 Differentiation rate using the naked eye of visible implant fluorescent elastomer (VIE) tags in each sites of marine medaka Oryzias dancena, from 0 to 12 months after VIE tagging

\begin{tabular}{|c|c|c|c|c|}
\hline \multirow[t]{2}{*}{ Month } & \multirow[t]{2}{*}{ Color } & \multicolumn{3}{|c|}{ Differentiation rate (\%) } \\
\hline & & Abdomen & Back & Caudal vasculature \\
\hline \multirow[t]{3}{*}{1} & Red & $60.0 \pm 4.21^{c}$ & $100.0^{a}$ & $100.0^{a}$ \\
\hline & Green & $84.0 \pm 3.67^{a}$ & $96.0 \pm 2.11^{c}$ & $100.0^{\mathrm{a}}$ \\
\hline & Yellow & $73.9 \pm 4.55^{\mathrm{b}}$ & $97.8 \pm 4.34^{b}$ & $96.3 \pm 3.11^{\mathrm{b}}$ \\
\hline \multirow[t]{3}{*}{3} & Red & $59.4 \pm 3.56^{c}$ & $97.0 \pm 1.55^{\mathrm{a}}$ & $100.0^{\mathrm{a}}$ \\
\hline & Green & $82.0 \pm 5.07^{a}$ & $93.2 \pm 4.74^{c}$ & $95.6 \pm 4.12^{b}$ \\
\hline & Yellow & $77.3 \pm 3.85^{\mathrm{b}}$ & $96.2 \pm 2.65^{b}$ & $94.3 \pm 3.01^{c}$ \\
\hline \multirow[t]{3}{*}{6} & Red & $59.8 \pm 4.21^{c}$ & $94.4 \pm 2.51^{\mathrm{a}}$ & $97.4 \pm 2.33^{\mathrm{a}}$ \\
\hline & Green & $80.3 \pm 6.47^{\mathrm{a}}$ & $92.3 \pm 5.78^{\mathrm{a}}$ & $96.9 \pm 2.11^{b}$ \\
\hline & Yellow & $75.7 \pm 4.68^{b}$ & $97.9 \pm 0.91^{a}$ & $96.3 \pm 2.97^{b}$ \\
\hline \multirow[t]{3}{*}{9} & Red & $62.4 \pm 3.93^{c}$ & $93.7 \pm 2.86^{b}$ & $98.6 \pm 3.12^{b}$ \\
\hline & Green & $84.4 \pm 5.41^{\mathrm{a}}$ & $93.7 \pm 0.74^{b}$ & $99.5 \pm 2.69^{\mathrm{a}}$ \\
\hline & Yellow & $74.8 \pm 5.23^{b}$ & $98.3 \pm 1.99^{\mathrm{a}}$ & $94.3 \pm 3.79^{c}$ \\
\hline \multirow[t]{3}{*}{12} & Red & $65.2 \pm 4.41^{c}$ & $92.1 \pm 4.61^{c}$ & $98.8 \pm 0.72^{\mathrm{a}}$ \\
\hline & Green & $85.9 \pm 2.38^{\mathrm{a}}$ & $94.0 \pm 1.68^{b}$ & $98.1 \pm 1.08^{\mathrm{a}}$ \\
\hline & Yellow & $68.5 \pm 5.53^{b}$ & $97.3 \pm 0.23^{\mathrm{a}}$ & $96.3 \pm 2.89^{b}$ \\
\hline
\end{tabular}

Samples tagged with VIE were investigated. Both dead samples and eliminated VIE tags were excluded from the analysis. Values are mean \pm S.E. $(n=50)$. The experiment was performed in triplicate. The values in each column that do not share a common superscript are significantly different from one another $(P<0.05)$

Table 3 Differentiation rate using the UV lamp of visible implant fluorescent elastomer (VIE) tags in each site of marine medaka, Oryzias dancena, from 0 to 12 months after VIE tagging

\begin{tabular}{|c|c|c|c|c|}
\hline \multirow[t]{2}{*}{ Month } & \multirow[t]{2}{*}{ Color } & \multicolumn{3}{|c|}{ Differentiation rate (\%) } \\
\hline & & Abdomen & Back & Caudal vasculature \\
\hline \multirow[t]{3}{*}{1} & Red & $88.0 \pm 2.61^{b}$ & $100.0^{\mathrm{a}}$ & $100.0^{\mathrm{a}}$ \\
\hline & Green & $92.0 \pm 1.73^{\mathrm{a}}$ & $100.0^{\mathrm{a}}$ & $100.0^{\mathrm{a}}$ \\
\hline & Yellow & $86.9 \pm 3.11^{c}$ & $100.0^{\mathrm{a}}$ & $100.0^{\mathrm{a}}$ \\
\hline \multirow[t]{3}{*}{3} & Red & $89.8 \pm 1.73^{b}$ & $100.0^{\mathrm{a}}$ & $100.0^{\mathrm{a}}$ \\
\hline & Green & $90.3 \pm 2.22^{\mathrm{a}}$ & $99.4 \pm 0.03^{b}$ & $100.0^{\mathrm{a}}$ \\
\hline & Yellow & $84.7 \pm 2.83^{c}$ & $100.0^{\mathrm{a}}$ & $100.0^{\mathrm{a}}$ \\
\hline \multirow[t]{3}{*}{6} & Red & $85.9 \pm 3.85^{c}$ & $100.0^{\mathrm{a}}$ & $99.4 \pm 0.01^{\mathrm{b}}$ \\
\hline & Green & $91.8 \pm 2.89^{\mathrm{a}}$ & $97.8 \pm 1.01^{c}$ & $98.9 \pm 1.07^{c}$ \\
\hline & Yellow & $87.5 \pm 3.10^{b}$ & $99.5 \pm 0.20^{b}$ & $100.0^{\mathrm{a}}$ \\
\hline \multirow[t]{3}{*}{9} & Red & $87.5 \pm 2.81^{c}$ & $100.0^{\mathrm{a}}$ & $99.1 \pm 0.04^{\mathrm{a}}$ \\
\hline & Green & $91.3 \pm 2.10^{\mathrm{a}}$ & $97.1 \pm 0.78^{c}$ & $98.2 \pm 1.10^{b}$ \\
\hline & Yellow & $88.1 \pm 1.08^{b}$ & $98.9 \pm 1.00^{b}$ & $98.5 \pm 0.74^{b}$ \\
\hline \multirow[t]{3}{*}{12} & Red & $87.2 \pm 3.02^{b}$ & $100.0^{\mathrm{a}}$ & $98.9 \pm 0.03^{\mathrm{a}}$ \\
\hline & Green & $95.0 \pm 2.97^{\mathrm{a}}$ & $96.9 \pm 1.61^{c}$ & $97.9 \pm 0.69^{b}$ \\
\hline & Yellow & $84.0 \pm 2.11^{c}$ & $98.3 \pm 0.57^{b}$ & $98.2 \pm 0.42^{\mathrm{a}}$ \\
\hline
\end{tabular}

Samples tagged with VIE were investigated. Both dead samples and eliminated VIE tags were excluded from the analysis. Values are mean \pm S.E. $(n=50)$. The experiment was performed in triplicate. The values in each column that do not share a common superscript are significantly different from one another $(P<0.05)$ 
tags. The abdomen tag retention rate was the lowest among the tagging sites.

We measured the visual differentiation of the tags using two detection methods (visible and UV lights) (Tables 2 and 3). During $1 \mathrm{~min}$, the VIE tags were initially observed using visible light at $30-\mathrm{cm}$ distance from the experimental fish. Table 2 shows the dead fish and those that eliminated the VIE tags were excluded from the analysis. For the abdomen site, the capacity to detect for the red and green tags was significantly greater than that for the yellow tags $(P<0.05)$. At 1 month, the detection rate of the red tags (\%) was $60.0 \pm 4.21$, for the green tags was $84.0 \pm 3.67$, and for the yellow tags was $73.9 \pm 4.55$. After 12 months, the values were $65.2 \pm 4.41,85.9 \pm 2.38$, and $68.5 \pm 1.53$, respectively, indicating that the red and green colors were more easily detected $(P<0.05)$. For the back site at 1 month, the detection rate (\%) of red tags was 100 , for green was $96.0 \pm 2.11$, and for yellow was $97.8 \pm 4.34$. After 12 months, tag detection were $92.1 \pm 4.61$ and $94.0 \pm 1.68$ for the red and green tags, respectively, and for the yellow tags was $97.3 \pm 0.23$. For the caudal vasculature at 1 month, the detection rates (\%) of red and green tags were 100, respectively, but for the yellow tags was $96.3 \pm 1.11$. At 6 months, the detection rates (\%) were $97.4 \pm 2.33$, $96.9 \pm 2.11$, and $96.3 \pm 1.97$, respectively $(P<0.05)$. At the end of the experiment, the detection rates (\%) were $98.8 \pm 1.72,98.1 \pm 1.08$, and $96.3 \pm 2.89$, respectively. Table 2 shows that abdomen tags were less well detected than back and caudal vasculature tags.

Table 3 shows the results for tag differentiation using the UV light for detection of the VIE tags at each site in the experimental fish. The observation protocol was as described above. For the abdomen site, the detection of the red and green tags was significantly greater than for the yellow tags $(P<0.05)$. At 1 month, the detection rate (\%) for the red tags was $88.0 \pm 2.61$, for green was $92.0 \pm 1.73$, and for yellow was $86.9 \pm 3.11$, indicating that the red and green tags were more readily detected than the yellow tags $(P<0.05)$. After 6 months, this had not changed significantly, and at the end of the experiment (12 months), the detection (\%) of the red, green, and yellow tags were $87.2 \pm 3.02,95.0 \pm 2.97$, and $84.0 \pm 2.11$, respectively, showing that the yellow tags were least detectable when observed by the UV light $(P<0.05)$. For the back site, the tag detection rate was $100 \%$ for the three colors, while at 12 months, for the red tags was 100.0, for the green was $96.9 \pm 1.61$, and for the yellow was $98.3 \pm 0.57(P<0.05)$. These results indicate that red tags were significantly more readily detected than green and yellow tags $(P<0.05)$. In addition, the back tags were detected more easily relative to those in the abdomen site. On the caudal vasculature, the detection rate (\%) of all the color tags were $100 \%$. After the 12 months of the experiment, the detection rate for the red tags (\%) was $98.9 \pm 0.03$, for the green was $97.9 \pm 0.69$, and for the yellow was $98.2 \pm 0.42$, indicating that red and yellow tags were more easily detected than green tags in the caudal vasculature. In conclusion, by UV lamp, the tag readability for the back and caudal vasculature sites were significantly greater than those for the abdomen site $(P<0.05$; Table 3$)$. Regardless of site, all color tags under UV light were more easily detected than all color tags under visible light.

During experimental period (12 months), accumulated survival rates of back, abdomen, and caudal vasculature groups were not significantly different among red, green, and yellow, respectively (Table $4, P>0.05$ ). However, accumulated survival rates of each color were affected by the tagging site (Table $4, P<0.05$ ). During 12 months, the accumulated survival (\%) of the control group was the highest $(P<0.05)$ and the reduction ratio of the accumulated survival in the control group was the most gradual. However, the accumulated survival (\%) of the abdomen group in each color were the lowest $(P<0.05)$, and the reduction ratio were the most dramatic in each color (Table 4).

Table 4 Accumulated survival rate using the UV lamp of visible implant fluorescent elastomer (VIE) tags in each site of marine medaka, Oryzias dancena, from 0 to 12 months after VIE tagging

\begin{tabular}{|c|c|c|c|c|c|}
\hline \multirow[t]{2}{*}{ Month } & \multirow[t]{2}{*}{ Color } & \multicolumn{4}{|c|}{ Accumulated survival rate (\%) } \\
\hline & & $\begin{array}{l}\text { Control } \\
\text { (no injection) }\end{array}$ & Abdomen & Back & $\begin{array}{l}\text { Caudal } \\
\text { vasculature }\end{array}$ \\
\hline \multirow[t]{3}{*}{0} & Red & $100.0^{\mathrm{a}}$ & $100.0^{\mathrm{a}}$ & $100.0^{\mathrm{a}}$ & $100.0^{\mathrm{a}}$ \\
\hline & Green & $100.0^{\mathrm{a}}$ & $100.0^{\mathrm{a}}$ & $100.0^{\mathrm{a}}$ & $100.0^{\mathrm{a}}$ \\
\hline & Yellow & $100.0^{\mathrm{a}}$ & $100.0^{\mathrm{a}}$ & $100.0^{\mathrm{a}}$ & $100.0^{\mathrm{a}}$ \\
\hline \multirow[t]{3}{*}{1} & Red & $100.0^{\mathrm{a}}$ & $85.7 \pm 0.71^{c}$ & $99.3 \pm 0.24^{a}$ & $97.5 \pm 0.41^{b}$ \\
\hline & Green & $100.0^{\mathrm{a}}$ & $85.0 \pm 1.14^{c}$ & $99.0 \pm 0.59^{a}$ & $97.9 \pm 0.87^{b}$ \\
\hline & Yellow & $100.0^{\mathrm{a}}$ & $85.9 \pm 1.06^{c}$ & $98.8 \pm 0.67^{\mathrm{a}}$ & $96.8 \pm 0.91^{b}$ \\
\hline \multirow[t]{3}{*}{3} & Red & $97.5 \pm 1.88^{\mathrm{a}}$ & $80.4 \pm 1.73^{c}$ & $97.3 \pm 1.89^{\mathrm{a}}$ & $93.6 \pm 1.41^{\mathrm{b}}$ \\
\hline & Green & $97.5 \pm 1.88^{\mathrm{a}}$ & $79.1 \pm 1.92^{c}$ & $97.2 \pm 1.14^{\mathrm{a}}$ & $94.1 \pm 0.92^{\mathrm{b}}$ \\
\hline & Yellow & $97.5 \pm 1.88^{\mathrm{a}}$ & $81.1 \pm 1.88^{c}$ & $97.8 \pm 0.91^{\mathrm{a}}$ & $93.6 \pm 1.10^{b}$ \\
\hline \multirow[t]{3}{*}{6} & Red & $96.1 \pm 2.84^{\mathrm{a}}$ & $77.1 \pm 3.24^{d}$ & $93.3 \pm 1.57^{b}$ & $86.4 \pm 2.14^{c}$ \\
\hline & Green & $96.1 \pm 2.84^{\mathrm{a}}$ & $76.7 \pm 2.88^{d}$ & $92.6 \pm 1.25^{\mathrm{b}}$ & $87.0 \pm 1.55^{c}$ \\
\hline & Yellow & $96.1 \pm 2.84^{\mathrm{a}}$ & $76.9 \pm 3.10^{d}$ & $93.4 \pm 1.09^{b}$ & $86.8 \pm 3.81^{c}$ \\
\hline \multirow[t]{3}{*}{9} & Red & $93.8 \pm 1.55^{\mathrm{a}}$ & $71.2 \pm 3.44^{d}$ & $90.7 \pm 2.48^{\mathrm{b}}$ & $81.1 \pm 4.39^{c}$ \\
\hline & Green & $93.8 \pm 1.55^{\mathrm{a}}$ & $70.4 \pm 4.05^{d}$ & $90.5 \pm 3.24^{b}$ & $80.1 \pm 3.81^{c}$ \\
\hline & Yellow & $93.8 \pm 1.55^{\mathrm{a}}$ & $71.2 \pm 2.12^{d}$ & $89.9 \pm 1.85^{b}$ & $81.1 \pm 2.58^{c}$ \\
\hline \multirow[t]{3}{*}{12} & Red & $90.4 \pm 2.88^{\mathrm{a}}$ & $64.2 \pm 4.32^{d}$ & $86.9 \pm 3.14^{b}$ & $74.1 \pm 2.89^{c}$ \\
\hline & Green & $90.4 \pm 2.88^{\mathrm{a}}$ & $63.8 \pm 4.75^{d}$ & $86.7 \pm 2.99^{b}$ & $74.6 \pm 3.09^{c}$ \\
\hline & Yellow & $90.4 \pm 2.88^{\mathrm{a}}$ & $64.3 \pm 4.02^{d}$ & $87.4 \pm 3.02^{b}$ & $73.5 \pm 2.77^{c}$ \\
\hline
\end{tabular}

Samples tagged with VIE were investigated. Values are mean \pm S.E. $(n=50)$. The experiment was performed in triplicate. The values in each column that do not share a common superscript are significantly different from one another $(P<0.05)$ 
In three colors of VIE tagging groups, the accumulated survival rates of the three sites and the control group were $100 \%$ at the initiation of experiment (Table 4). Accumulated survival (\%) of the control group declined gradually to $90.4 \pm 2.88$ during 12 months. In addition, accumulated survival (\%) of the back group in three colors declined gradually during 12 months. However, the abdomen group declined drastically to $64.2 \pm 4.32$ in red, $63.8 \pm 4.75$ in green, and $64.3 \pm 4.02$ in yellow during 12 months, respectively. Accumulated survival (\%) of the caudal vasculature group in three colors declined gradually to $93.6 \pm 1.41$ in red, $94.1 \pm 0.92$ in green, and $93.6 \pm 1.10$ in yellow until 3 months after injection and declined drastically to $74.1 \pm 2.89$ in red, $74.6 \pm 3.09$ in green, and $73.5 \pm 2.77$ in yellow until 12 months after injection. In summary, the experimental fish of three colors survived $>85 \%$ of the tags injected in the back, $>70 \%$ of the tags injected in the caudal vasculature, and $>60 \%$ of the tags injected in the abdomen (Table $4, P<0.05$ ).

The whole-body cortisol concentration variations of the tagged group during $48 \mathrm{~h}$ are shown in Fig. 3. The whole-body cortisol concentration of the control groups was $0.9 \mu \mathrm{g} / \mathrm{dL}$ and has been increased to $1.20 \mu \mathrm{g} / \mathrm{dL}$ in $1 \mathrm{~h}$ and became $5.10 \mu \mathrm{g} / \mathrm{dL}$ in $6 \mathrm{~h}$. After $12 \mathrm{~h}$, it rather decreased to $1.26 \mu \mathrm{g} / \mathrm{dL}$ a bit and became $0.90 \mu \mathrm{g} / \mathrm{dL}$ in $24 \mathrm{~h}$ and $0.86 \mu \mathrm{g} / \mathrm{dL}$ in $48 \mathrm{~h}$. The whole-body cortisol concentrations of caudal vasculature, abdomen, and back tagged groups were $0.81,0.92$, and $1 \mu \mathrm{g} / \mathrm{dL}$, respectively, and has been rapidly increased to $14.76,15.60$, and $15.49 \mu \mathrm{g} / \mathrm{dL}$ in $1 \mathrm{~h}$ and increased drastically in $6 \mathrm{~h}$ $(P<0.05)$. The whole-body cortisol concentrations of the three experimental groups were the highest at $12 \mathrm{~h}$, and became $29.43,29.80$, and $30.43 \mu \mathrm{g} / \mathrm{dL}$, respectively. In $24 \mathrm{~h}$, the whole-body cortisol concentrations of the three groups decreased rapidly until $48 \mathrm{~h}(P<0.05)$. The tagging sites were not affected significantly in whole-body cortisol concentration $(P>0.05)$, and the change of whole-body cortisol concentration according to exposure was seen compared to that at pre-experiment and the cortisol concentration was the highest at $6 \mathrm{~h}$ in the control group. However, the cortisol concentration was the highest at $12 \mathrm{~h}$ in the three experimental groups.

The whole-body glucose and lactic acid concentration variations of tagged marine medaka during $48 \mathrm{~h}$ are shown in Figs. 4 and 5. The whole-body glucose and lactic acid concentrations of the control groups were $25 \mathrm{mg} / \mathrm{dL}$ and $0.8 \mathrm{mmol} / \mathrm{L}$, respectively, and have been rapidly increased to $55 \mathrm{mg} / \mathrm{dL}$ and $1.48 \mathrm{mmol} / \mathrm{L}$ in $12 \mathrm{~h}(P<0.05)$. At $48 \mathrm{~h}$, it rather decreased to $38 \mathrm{mg} / \mathrm{dL}$ and $1.0 \mathrm{mmol} / \mathrm{L}$ $(P<0.05)$. The whole-body glucose concentrations of three experimental groups were increased rapidly from 12 to $24 \mathrm{~h}$ and decreased drastically from 24 to $48 \mathrm{~h}$. The whole-body glucose concentrations of the three experimental groups were the highest at $24 \mathrm{~h}$. The lactic acid concentrations of the three experimental groups were increased rapidly from 24 to $48 \mathrm{~h}(P<0.05)$. The lactic acid concentrations of the three experimental groups were the highest at $48 \mathrm{~h}$. The lactic acid concentrations of the three tagged groups were not observed of reduction while at $48 \mathrm{~h}$. Tagging sites were not affected significantly in whole-body glucose and lactic acid concentration $(P>0.05)$. The change of whole-body glucose concentration according to exposure was seen compared to that at pre-experiment, and the whole-body glucose and lactic acid concentrations were the highest at $12 \mathrm{~h}$ in the control group. However, the times observed when the highest glucose and lactic acid concentrations of the three groups were delayed were 24 and $48 \mathrm{~h}$.

\section{Discussion}

In assessing the tagging sites for fish, it is important to establish the effect of the tag, including the tag retention at

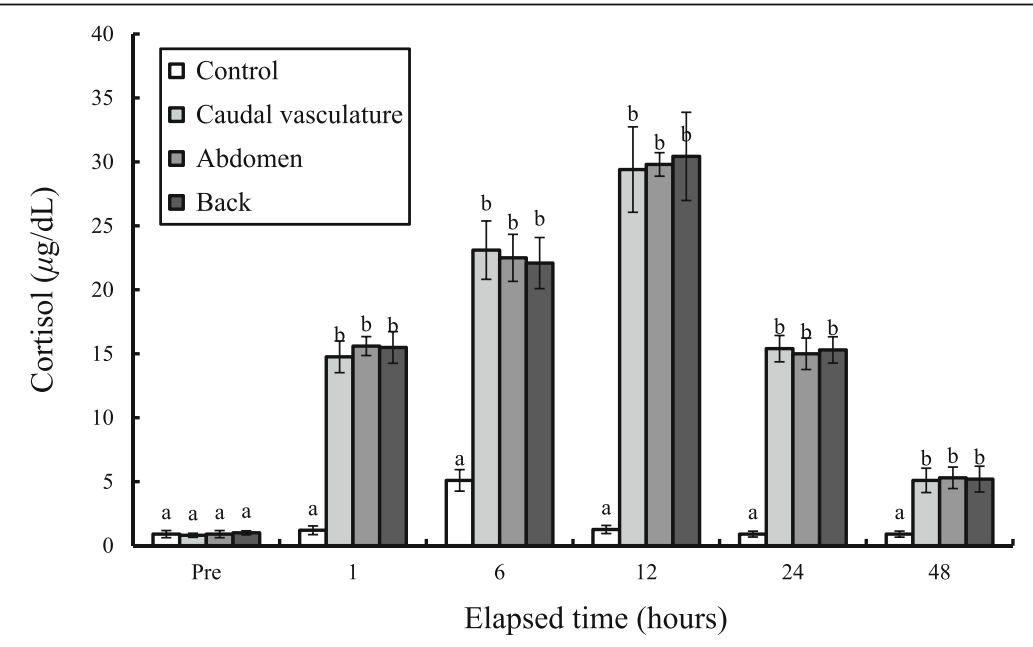

Fig. 3 The whole-body cortisol concentration variations of the tagged marine medaka, Oryzias dancena, during $48 \mathrm{~h}$ 


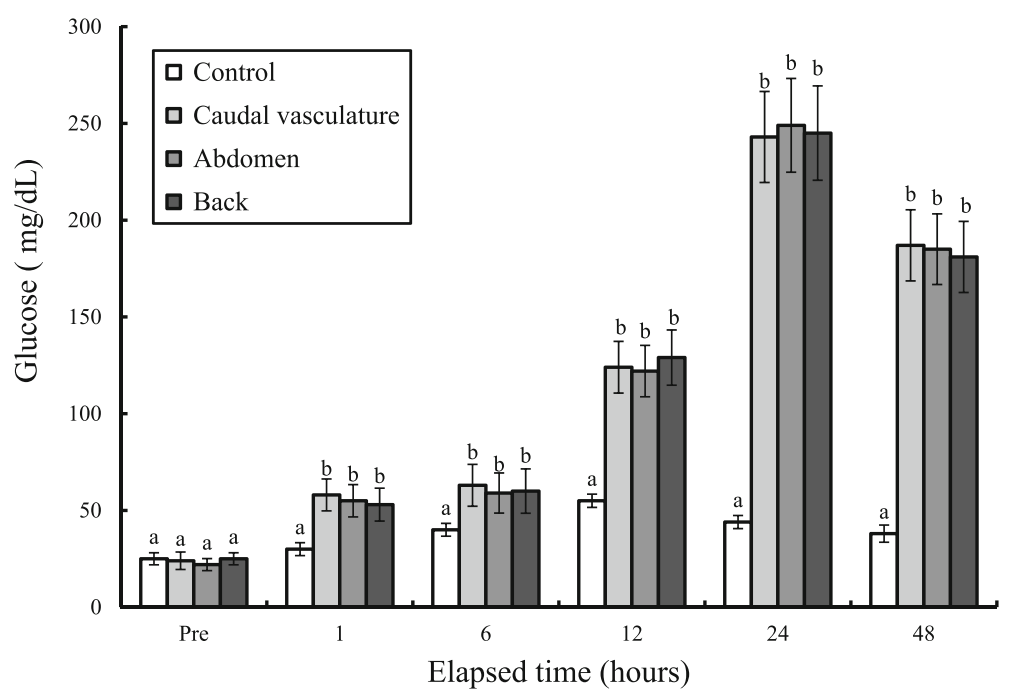

Fig. 4 The whole-body glucose variations of the tagged marine medaka, Oryzias dancena, during $48 \mathrm{~h}$

the tagging site, the rate of tag detection following the tagging site, and the survival rate of the tagged fish (Frederick, 1997; Dewey and Zigler, 1996; Park et al., 2013; Willis and Babcock, 1998). Statistically significant differences were found among tag colors and sites, with red and green tags being easier to detect and distinguish under visible and UV lights than yellow tags in marine medaka, O. dancena. In contrast, Park et al. (2013) reported that red and orange were easier to detect and identify than green and yellow when viewed under UV light, but green and yellow were easily detected in visible light in a greenling, Hexagrammos otakii. However, as in the current study, red tags were more easily detected than green or yellow tags (Willis and Babcock, 1998). In deeper water, where natural light levels are lower, greater attenuation of red light may occur (Willis and Babcock, 1998). In direct sunlight, red tags were clearly detectable at up to $5 \mathrm{~m}$ distant in clear water (Pottinger and Calder, 1995).

As shown in Fig. 3, the VIE tag affected the survival of marine medaka in the laboratory $(P<0.05)$. In conclusion, survival was significantly higher in the control group than in any of the experimental groups. Among the experimental groups, fish tagged in the abdomen site showed the lowest survival. Therefore, skilled injection of the elastomer is crucial for keeping the mortality low, as suggested by the decrease in mortality of marked fish during the laboratory experiment (Frederick, 1997). In previous study, the primary causes of mortality among the tagged

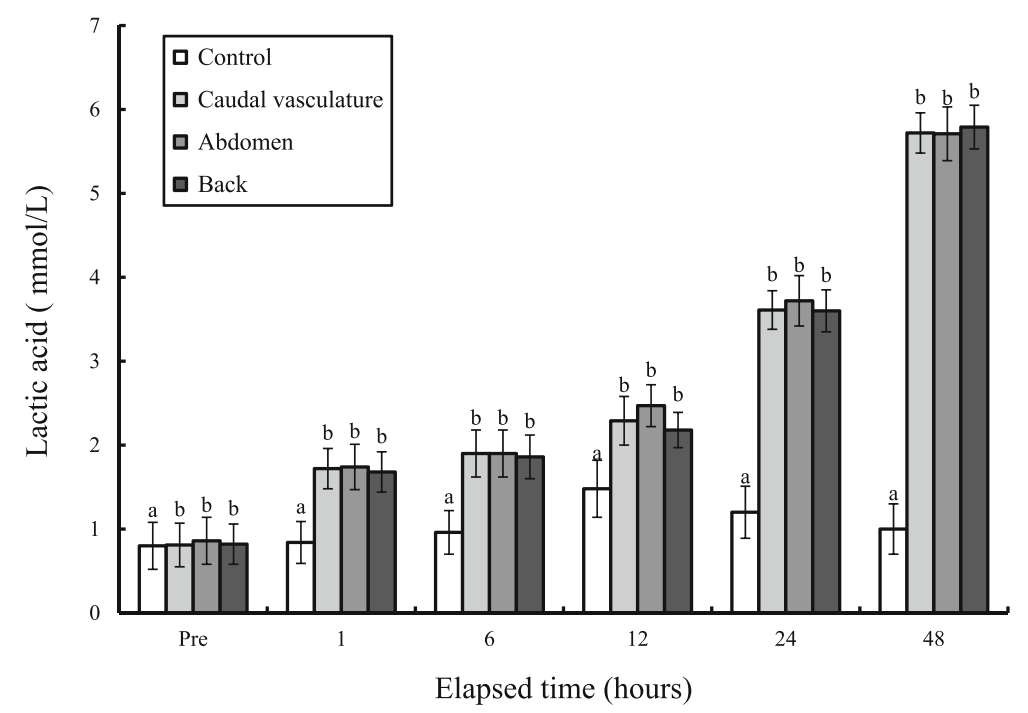

Fig. 5 The whole-body lactic acid concentration variations of the tagged marine medaka, Oryzias dancena, during $48 \mathrm{~h}$ 
samples were internal damage and infection, as a result of gas bladder rupture, and infection from anatomical trauma caused by handling (Willis and Babcock, 1998). The causes of mortality among experimental groups were not determined in this study, and histological observations of post-mortem samples are necessary for investigating the causes of mortality. The results of this experiment are similar to those of the previous studies showing high retention of VIE (Dewey and Zigler, 1996; Willis and Babcock, 1998) in the marine medaka, which had $>90 \%$ tag retention for the back tagging site (Table 1), with the caudal vasculature and the abdomen having lower tag retention rates. The various characteristics of this species must be investigated to determine the greater loss of VIE tag retention for the caudal vasculature and the abdomen sites during the experimental period.

The use of VIE tagging in small fish, marine medaka, is advocated as a practical and reliable method for fish identification and monitoring, but it may cause negative effects on growth and mortality. Foreign materials such as tags can lead to stress and may cause changes of the blood reactions of fish. When stress is induced, the fish consume energy, which drives a response of excess secretion of catecholamine and cortisol, and has a considerable influence on the maintenance of homeostasis (Schreck et al., 2001). Plasma cortisol and plasma glucose are recognized as useful indicators of stress in fish (Schreck et al., 2001). In our study, whole-body physiological responses of marine medaka from each tagging region, in the form of high whole-body cortisol, wholebody glucose, and lactic acid values, were generally observed in tagged groups in which a tag had actually been inserted compared to the responses seen in control groups. This finding indicates that the actual insertion of a tag rather than just a pierce injection can result in added stress, and this result shows that tagging sites were not affected significantly in stress response.

The plasma cortisol levels induced by stress appear to increase at various speed and time according to the species of fish (Pickering and Pottinger, 1989). The plasma cortisol concentration after stress is usually reported to increase to a peak value within $1 \sim 3 \mathrm{~h}$ and normally recovers within $6 \mathrm{~h}$ (Willis and Babcock, 1998). As a whole, the whole-body cortisol values for the tagged group were similar to the values seen in the control group after $48 \mathrm{~h}$. Therefore, the time required for the black rockfish to adapt after the insertion of a tag is approximately $48 \mathrm{~h}$. The whole-body cortisol concentrations showed peak values before $48 \mathrm{~h}$ in this study. The trends in cortisol and glucose observed in this experiment indicated generalized stress reactions. Glucose formation was increased simultaneously as the cortisol quantity increased. Elevated cortisol secretion under stress increases the activation of plasma glucose by the activity of the gluconeogenesis enzyme; also, this increase is the result of a second reaction to the first reaction (response of hormone) to stress (Barton and Iwama, 1991).

Buckley et al. (1994) found that in juvenile reef fish, Sebastes spp., the VIE tags could be detected visually in situ for up to 258 days using underwater UV lights. In response to concerns about amphibian declines, Jung et al. (2000) evaluated and validated amphibian monitoring techniques using VIE tags in studies in the Shenandoah and Big Bend national parks, USA. Godin et al. (1995) found that to identify populations of shrimp, Penaeus vannamei, individuals could be tagged internally using an externally visible elastomer. Basic considerations in the use of tags in fisheries management or research include the effects of the tags on animal survival, behavior, growth, permanency, and recognition and the cost of the marking technique (McFarlane and Beamish, 1990; Park and Lee, 2001). VIE tags are made of non-toxic medical grade fluorescent elastomer material and have been used successfully to identify fish, amphibians, and decapod crustaceans (Willis and Babcock, 1998; Jerry et al., 2001; Bailey, 2004). The retention rate was $92 \%$ for visual implant elastomer (VIE) tags in juvenile crayfish, Cherax destructor, and $100 \%$ for VIE tags in lobsters, Homarus gammarus (Jerry et al., 2001; Uglem et al., 1996). As with VIE tags, passive inductive transponder (PIT) tags are sometimes used in experiments. However, in a study involving injection of small, mid-sized, and large tags into four small Cyprinidae fish species, Carassius gibelio langsdorfi, Hypophthalmichthys molitrix, Pseudorasbora parva, and Phoxinus phoxinus, Jang et al. (2007) reported that PIT tags caused high mortality. The larger and heavier PIT tags can affect the swimming ability of small fish, including marine medaka. Thus, Jang et al. (2007) concluded that PIT tags are inappropriate for small individuals. So, the VIE tags are small, light, and made of non-toxic medical grade fluorescent elastomer material and are therefore more appropriate for small individuals and species, including marine medaka, and are considered effective for laboratory experiments and aquaculture facilities. Unfortunately, the relationship among decreasing survival rate, spawning behavior, and VIE tag was not determined by the previous studies. Thus, future investigation will focus on the relationship among reduced survival rates, spawning behavior, and VIE tag.

\section{Conclusions}

During 12 months, the accumulated survival rates of marine medaka, Oryzias dancena, in the experimental treatments were not different among red, yellow, and green elastomer. The experimental fish retained $>85 \%$ of the tags injected in the back, $>70 \%$ of the tags injected 
in the caudal vasculature, and $>60 \%$ of the tags injected in the abdomen. For all injected sites the red and green tags were able to be detected more easily than the yellow tags when observed under both visible and UV light. So, the VIE tags are small, light, and made of non-toxic medical grade fluorescent elastomer material and are therefore more appropriate for small individuals and species, including marine medaka, and are considered effective for laboratory experiments and aquaculture facilities.

\section{Abbreviations}

PIT: Passive integrated tag; VIE: Visible implant fluorescent elastomer

\section{Acknowledgements}

The authors thank the technical staff of the Cheongpyeong Aquaculture Research Center, NIFS, Korea, and the Laboratory for Fishery Genetics and Breeding Sciences at the Korea Maritime and Ocean University, South Korea, for their helpful support, and the anonymous reviewers who greatly improved the quality of this manuscript.

\section{Funding}

This work was supported by a grant from the National Institute of Fisheries Science (R2017038) from the Inland Fisheries Research Institute, National Institute of Fisheries Science (NIFS), South Korea.

\section{Availability of data and materials}

Not applicable.

\section{Authors' contributions}

$\mathrm{JHI}, \mathrm{CYC}, \mathrm{KWY}, \mathrm{CHK}$, and BSKS designed the overall plan of the experiment and drafted this manuscript. HYG, ISP, and THL conducted the whole part of the experiment, for example, inserting PIT tags into a sample. All authors read and approved the manuscript.

\section{Ethics approval and consent to participate} Not applicable.

\section{Consent for publication}

Not applicable.

\section{Competing interests}

The authors declare that they have no competing interests.

\section{Publisher's Note}

Springer Nature remains neutral with regard to jurisdictional claims in published maps and institutional affiliations.

\section{Author details}

'Research Cooperation Division, National Institute of Fisheries Science (NIFS), Busan 46083, South Korea. ${ }^{2}$ Division of Marine Bioscience, College of Ocean Science and Technology, Korea Maritime and Ocean University, 727 Taejong-ro, Yeong do-gu, Busan 49112, South Korea. ${ }^{3}$ Food, Agriculture, Forestry and Fisheries Examination Division, Korean Intellectual Property Office, Daejeon 35208, South Korea. ${ }^{4}$ Inland Fisheries Research Institute, National Institute of Fisheries Science (NIFS), Cheongpyeung 12453, South Korea.

Received: 8 April 2017 Accepted: 22 August 2017

Published online: 13 September 2017

\section{References}

Bailey LL. Evaluating elastomer marking and photo identification methods for terrestrial salamanders: marking effects and observer bias. Herpetol Rev. 2004;35:38-41.

Barrett NS. Short- and long-term movement patterns of six temperate reef fishes (families Labridae \& Monacanthidae). Mar Freshw Res. 1995;46:853-60.
Barton BA, Iwama GK. Physiological changes in fish from stress in aquaculture with emphasis on the response and effects of corticosteroids. Ann Rev Fish Dis. 1991;1:3-26.

Bergman PK, Haw F, Blankenship HL, Buckley RM. Perspectives on design, use, and misuse of fish tags. Fisheries. 1992;17:20-5.

Buckley RM, West JE, Doty DD. Internal micro-tag systems for marking juvenile reef fishes. Bull Mar Sci. 1994;55:850-95.

Cho YS, Lee SY, Kim DS and Nam YK. 2010. Tolerance capacity to salinity change in adult and larva of Oryzias dancena, a euryhaline medaka. [Korean] Kor J Ichthyol 21, 9-16.

Cody RC, Smith JK. Applied statistics and the SAS programming language. 3rd ed. Englewood Cliffs: Prentice Hall; 1991. p. 122-35.

Connell SD, Jones GP. The influence of habitat complexity on postrecruitment processes in a temperate reef fish population. J Exp Mar Biol Ecol. 1991;151:271-94.

Crossland J. Snapper tagging in north-east New Zealand, 1974: analysis of methods, return rates, and movements. N Z J Mar Freshwater Res. 1976;10:675-86.

Crossland J. Population size and exploitation rate of snapper, Chrysophrys auratus, in the Hauraki Gulf from tagging experiments. 1975-76. N Z J Mar Freshwater Res. 1980;14:255-61.

Dewey MR, Zigler SJ. An evaluation of fluorescent elastomer for marking bluegills in experimental studies. Prog Fish Cult. 1996:58:219-20.

Duncan DB. Multiple-range and multiple F tests. Biometrics. 1955;11:1-42.

Forrester GE. Factors influencing the juvenile demography of a coral reef fish. Ecology. 1990;71:1666-81.

Frederick JL. Evaluation of fluorescent elastomer injection method for marking small fish. Bull Mar Sci. 1997;61:399-408.

Godin DM, Carr WH, Hagino G, Segura F, Sweeney JN, Blankenship L. Evaluation of a fluorescent elastomer internal tag in juvenile and adult shrimp, Penaeus vannamei. Aquaculture. 1995;139:243-8.

Inoue K, Takei Y. Asian medaka fishes offer new models for studying mechanisms of seawater adaptation. Comp Biochem Physiol B Biochem Mol Biol. 2003:136:635-45.

Jang MH, Yoon JD, Do YN, Joo GJ. Survival rate on the small cyprinidae by PIT tagging application. [Korean] Kor J Ichthyol. 2007;19:371-7.

Jerry DR, Stewart T, Purvis IW, Piper LR. Evaluation of visible implant elastomer and alphanumeric internal tags as a method to identify juveniles of the freshwater crayfish, Cherax destructor. Aquaculture. 2001;193:149-54.

Jones GP. Competitive interactions among adults and juveniles in a coral reef fish. Ecology. 1987;68:1534-47.

Jung RE, Droege S, Sauer JR, Landy RB. Evaluation of terrestrial and streamside salamander monitoring techniques at Shenandoah National Park. Environ Monitor Assess. 2000;63:65-79.

McFarlane GA, Beamish RJ. Effect of an external tag on growth of sablefish (Anoplopoma fimbria), and consequences to mortality and age at maturity. Can J Fish Aquat Sci. 1990;47:1551-7.

Nam YK, Cho YS, Lee SY, Kim DS. Tolerance capacity to salinity changes in adult and larva of Oryzias dancena, a euryhaline medaka. [Korean] Kor J Ichthyol. 2010;22:9-16.

Park I-S, Kim YJ, Gil HW, Kim D-S. Evaluation of implant fluorescent elastomer tagging greenling, Hexagrammos otakii. Fish Aquat Sci. 2013;16:35-9.

Park I-S, Lee K-K. The effective location of visible implant tags for short-term marking in Nile tilapia (Oreochromis niloticus: Cichlidae). J Fish Sci Tech. 2001:4:159-61.

Park I-S, Park SJ, Gil HW, Nam YK, Kim DS. Anesthetic effects of clove oil and lidocaine-HCl on marine medaka, Oryzias dancena. Lab Animal. 2011;40:45-51.

Parker ROJ. Tagging studies and diver observations of fish populations on livebottom reefs of the U.S. southeastern coast. Bull Mar Sci. 1990:46:749-60.

Pickering AD, Pottinger TG. Stress responses and disease resistance in salmonid fish: effects of chronic elevation of plasma cortisol. Fish Physiol Biochem. $1989 ; 7: 253-8$

Pottinger TG, Calder GM. Physiological stress in fish during toxicological procedures: a potentially confounding factor. Environ Toxicol Water Qual. 1995;10:135-46.

Pottinger TG, Carrick TR, Yeomans WE. The three-spined stickleback as an environmental sentinel: effects if stressors on whole-body physiological indices. J Fish Biol. 2002;61:207-29.

Raabo E, Terkildsen TC. On the enzymatic determination of blood glucose. Scandina J Clinic Lab Invest. 1960;12:402-7.

Ralston SL, Horn MH. High tide movements of the temperate-zone herbivorous fish Cebidichthys violaceus (Girard) as determined by ultrasonic telemetry. J Exp Mar Biol Ecol. 1986;98:35-50. 
Redding JM, Schreck CB. Influence of ambient salinity on osmoregulation and cortisol concentration of yearling coho salmon during stress. Trans Amer Fish Soc. 1983;112:800-7.

Song HY, Nam YK, Bang I-C, Kim DS. Early gonadogenesis and sex differentiation of marine medaka, Oryzias dancena (Beloniformes; Teleostei). [Korean] Kor J Ichthyol. 2009;21:141-8.

Serafy JE, Lutz SJ, Capo TR, Ortner PB, Lutz PL. Anchor tags affect swimming performance and growth of juvenile red drum, Sciaenops ocellatus. Mar Freshw Behav Physiol. 1995;27:29-35.

Schreck CB, Contreras-Sanchez W, Fitzpatrick MS. Effects of stress on fish reproduction, gamete quality, and progeny. Aquaculture. 2001;197:3-24.

Thompson SM, Jones GP. Social inhibition of maturation in females of the temperate wrasse Pseudolabrus celidotus and a comparison with the blennioid Tripterygion varium. Mar Biol. 1980;59:247-56.

Tong L. Tagging snapper Chrysophrys auratus by scuba divers. N Z J Mar Freshwater Res. 1978;12:73-6.

Uglem I, Noess H, Farestveit E, Jorstad KE. Tagging of juvenile lobsters (Hamarus gammarus (L.)) with visible implant fluorescent elastomer tags. Aquac Eng. 1996;15:499-501.

Willis TJ, Babcock RC. Retention and in situ detectability of visible implant fluorescent elastomer (VIE) tags in Pagrus auratus (Sparidae). N Z J Mar Freshwater Res. 1998:32:247-54.

Zerrenner A, Josephson DC, Krueger CC. Growth, mortality, and mark retention of hatchery brook trout marked with visible implant tags, jaw tags, and adipose fin clips. Prog Fish Cult. 1997;59:241-5.

\section{Submit your next manuscript to BioMed Central} and we will help you at every step:

- We accept pre-submission inquiries

- Our selector tool helps you to find the most relevant journal

- We provide round the clock customer support

- Convenient online submission

- Thorough peer review

- Inclusion in PubMed and all major indexing services

- Maximum visibility for your research

Submit your manuscript at www.biomedcentral.com/submit 